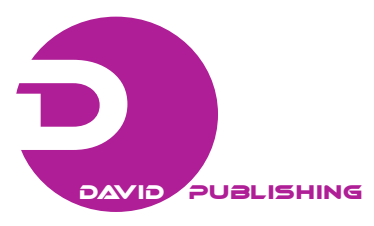

\title{
Analysis of Morphological Processes in a Disturbed Gravel-Bed River (Piave River): Integration of LiDAR Data and Colour Bathymetry
}

\author{
Fabio Delai, Johnny Moretto, Lorenzo Picco, Emanuel Rigon, Diego Ravazzolo and Mario Aristide Lenzi \\ Department of Land Environment Agriculture and Forestry, University of Padova, Legnaro 35020, Italy
}

\begin{abstract}
The magnitude of river morphological changes are better analyzed through the use of quantitative approaches, wherein resolution accuracy and uncertainty assessment are treated as crucial key-factors. In this sense, the creation of precise DEMs (Digital Elevation Models) of rivers represents an affordable tool to analyze geomorphic variations and budgets, except for wetted areas, where reliable channel digitalization can normally be obtained only using expensive bathymetric surveys. The proposed work aims at improving channel surface models without having available bathymetric sensors, by deriving dry areas elevations from LiDAR data and water depth of wetted areas from aerial photos through a predictive depth-colour relationship. The methodology was applied to two different sub-reaches of the Piave River, a gravel-bed river which suffered severe flood events in 2010. Erosion and deposition patterns were identified through DEM differencing, showing a predominance of scour processes which can lead to channel instability situations. The bathymetric output was compared to other previously-derived models confirming the accuracy of the in-channel elevation estimates. Finally, a discussion on the role played by longitudinal protections during the studied flood events is proposed, focusing the attention on the incidence of two major bank erosions that removed significant volumes of stable areas.
\end{abstract}

Key words: Colour bathymetry, LiDAR data, flood impacts, fluvial erosion-deposition processes, effect of river protections.

\section{Introduction}

Rivers shape the landscape through erosion, transport and deposition processes [1]. A large array of factors influences the morphological dynamics of many rivers. These factors can be either natural or human-induced and can act at different spatial and temporal scales. In this sense, river morphology investigates the evolution of fluvial environments through the analysis of qualitative and quantitative aspects [2-9].

In the last years, the advances in survey technologies have developed to rapidly acquire high resolution data over large spatial scales [10-12]. Different data collection methods have proven to be consistent in the production of high accuracy DEMs (Digital Elevation

Corresponding author: Mario Aristide Lenzi, professor, research fields: fluvial geomorphology, sediment transport in mountain streams and gravel-bed rivers, dynamics of large wood in rivers, effects of human interventions on river processes. E-mail: marioaristide.lenzi@unipd.it.
Models) of fluvial environments. Data collection methods include both passive, such as photogrammetry $[13,14]$ or digital image processing [15], and active, such as LiDAR [16, 17] or acoustic, technologies [18].

During data collection, a decisive role in our ability to detect true change is played by uncertainty in the data survey and processing. This is especially prevalent in areas with water or very dense vegetation. In these locations noise from error propagation often exceeds our ability to measure real change [19]. For instance, near-infrared laser pulses emitted by most LiDAR systems (with the exception of green LiDAR) are unable to provide topographic information of submerged areas of the channel, except for zones with very shallow water [20,21]. The recent development of bathymetric LiDAR technologies has enabled reliable modeling of river bed surfaces, nevertheless, these types of sensors come at an extremely high cost, produce scarce data quality and relatively rough 
resolutions [22].

To avoid these problems, the topography of wetted areas can be measured by calibrating depth-reflectance relationships using grey-scale [23], colour-scale $[14,15]$ and multispectral imagery $[24,25]$. Depth-reflectance relationships need to be further calibrated using control points derived from field survey contemporary to image acquisition.

Among river processes, bank erosion is one of the most important, as it is the process by which sediment is remobilized from storage in the floodplain. Sediment is eroded from banks through three main mechanisms: mass failure, sub-aerial weakening and fluvial entrainment [26]. Rates and magnitudes of bank erosion are affected by the amount and type of vegetation on the banks. Forested banks are normally the most resistant to erosion due to their greater soil compactness exerted by plant and grass roots [27]. In degraded systems, bank erosion leads to soil and land losses, which affect agricultural and recreational lands. More importantly, erosion represents a hazard when damages occur in populated areas (i.e., near roads, buildings and subsurface infrastructures). To prevent and control riverbank erosion, extensive protection measures have been taken in the last century in many European fluvial environments. These interventions produce many negative and unforeseen effects, specifically when bank stabilization works are outside of a comprehensive management policy. In some cases, poorly planned stabilization works have resulted in shifting the hazards downstream of the mitigation area [28, 29].

Even though an exhaustive study of the consequences of bank protection measures (and in general, of the wide array of river human interventions) is still missing, a new perception aimed at removing or replacing river structures with more natural methods and thus preserving the river evolutionary space seems to be the prevailing mindset.

This study aims at investigating channel depths through the calibration of an empirical model relating colour bands, derived by aerial photos, to channel depth. The correlation will provide bathymetric points which, after a filtering process, will be joined to dry areas points obtained by LiDAR. The final output will be Digital Terrain Models based on hybrid surveys (Hybrid Digital Terrain Models). Further geomorphic analyses will be presented indicating, on the basis of DoDs (DEMs of Difference), which process, between erosion and deposition, has prevailed during the severe flood events of November and December 2010. An interesting focus on the dynamics of two eroding banks that are immediately downstream of a historic bank stabilization project will be finally presented.

The detailed objectives include: (1) the definition of bathymetric models to represent accurately wet areas using the methodology of Moretto et al. [5]; (2) the final production of Digital Terrain Models derived by hybrid surveys (bathymetric and LiDAR); (3) the investigation of limitations and potentials of the representation method focusing on the factors influencing output quality; (4) the quantitative analysis of geomorphic changes occurred after the 2010 flood events, especially regarding the incidence of two major bank erosions of stable areas and their relation with upstream longitudinal protections.

\section{Study Area}

The Piave River basin (drainage area 3,900 $\mathrm{km}^{2}$ ) lies in the Eastern Italian Alps, flowing south from its headwaters for $220 \mathrm{~km}$ to the Adriatic Sea, near to Venice. The climate is temperate-humid with an average annual precipitation of about $1,350 \mathrm{~mm}$. The basin geology is composed mainly of sedimentary rocks with a little presence of volcanic and metamorphic rocks. The study reach of the Piave River is located mid-basin and is characterized by a multithread channel pattern. Two study reaches have been selected: reach one (Belluno) is approximately $2.2 \mathrm{~km}$ and reach two (Praloran) approximately $3.2 \mathrm{~km}$ long. The drainage area at the Belluno gauging station is $1,965 \mathrm{~km}^{2}$ (Fig. 1). River morphology in the study 


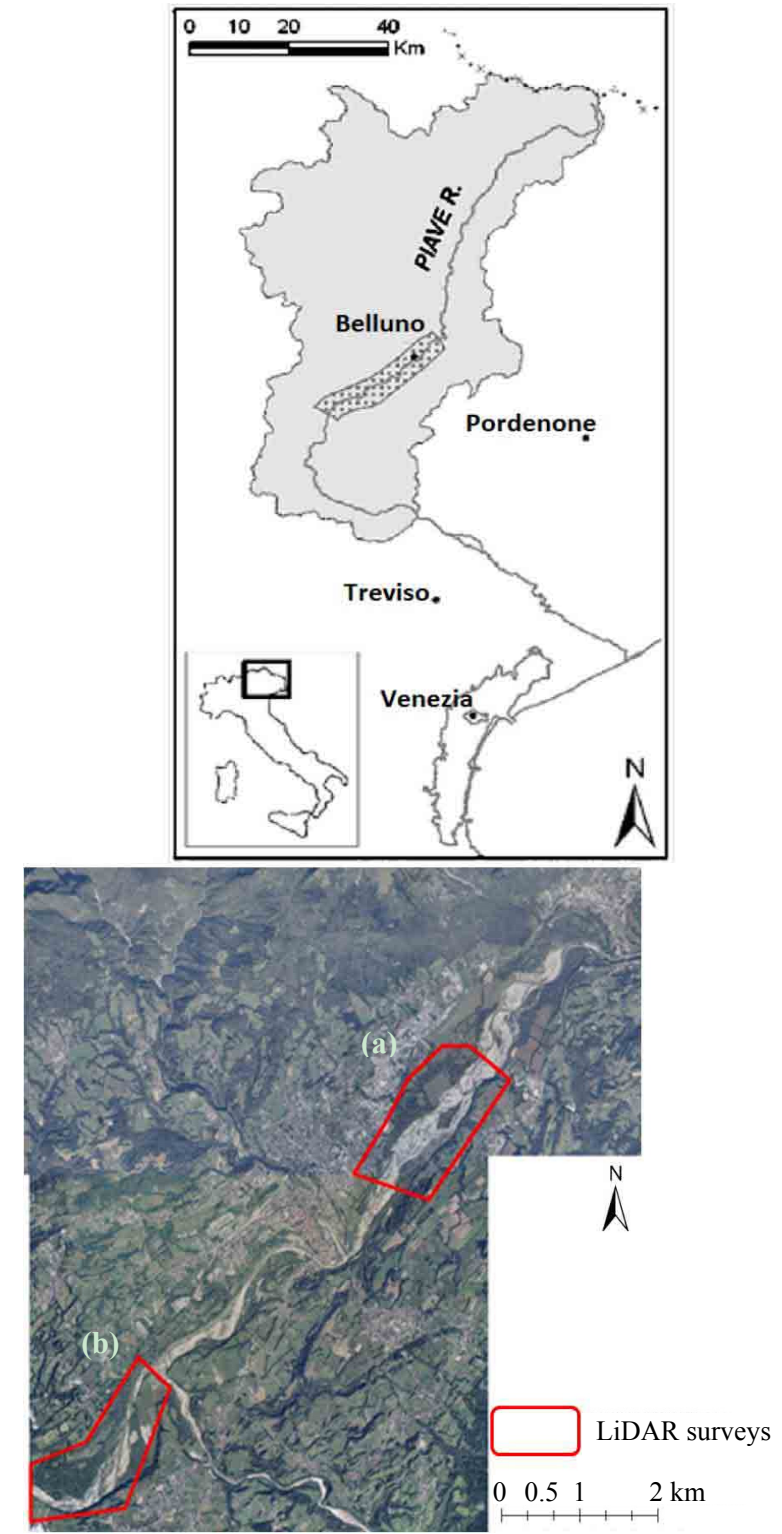

Fig. 1 Piave River and study sub-reaches: (a) Belluno; (b) Praloran.

sub-reaches is dominated by braided and wandering channel patterns, slope is around $0.45 \%$, and $\mathrm{D}_{50}$ ranges between $20 \mathrm{~mm}$ and $50 \mathrm{~mm}[4,9]$.

The Piave River is highly impacted by heavy gravel mining activities, which peaked during the time period of 1960 to 1990 [4].

\section{Materials and Methods}

Three different data sources were utilized to create the hybrid DTMs. LiDAR, DGPS (Differential Global Positioning System) data and aerial photographs were acquired contemporary. Using the methodology from Moretto et al. [5] bathymetric data were derived from water depth by calibrating a regression model between the Z-detrended DGPS coordinate and the photo colour bands (red, green and blue). From this correlation, accurate surface models accounting for more precise channel-bed elevations were developed.

\subsection{Data Capture}

Two LiDAR surveys were commissioned and operated before and after flood events occurred in November-December 2010 (Fig. 2). The first flight was carried out on the 23rd of August 2010 by Blom GCR SpA using an OPTECH ALTM Gemini Sensor. The second flight was operated on the 23rd of February 2011. Flight height for both collection flights was approximately $850 \mathrm{~m}$. Data acquisition times were selected based on weather and low water level conditions. Point density was at least two ground points per $\mathrm{m}^{2}$ and average vertical error was estimated through DGPS points comparison in the final surface models. The resulting DTM resolution was $0.5 \mathrm{~m}$ cell-size.

A series of RGB aerial images $(0.15 \mathrm{~m}$ pixel resolution) was flown during the LiDAR acquisition. Finally, contemporary DGPS points were taken covering different morphological units and water stages. In total, 537 DGPS points in 2010 and 4,006 DGPS points in 2011 were surveyed (DGPS average vertical error $\pm 0.025 \mathrm{~m}$ ).

\subsection{Dataset Preparation}

Aerial images were georeferenced and their brightness refined within the semi-automatic program

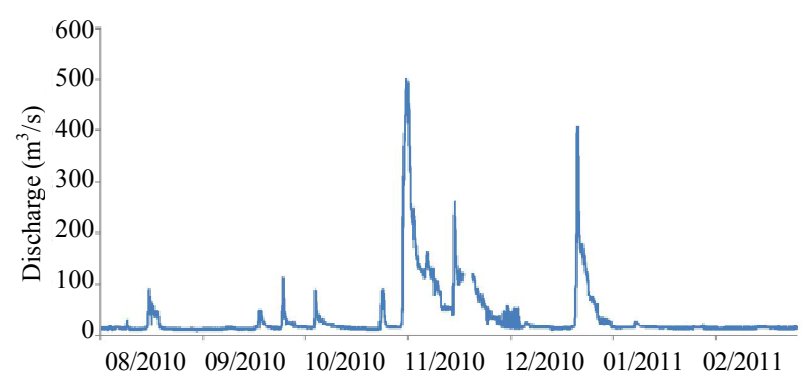

Fig. 2 Hourly water discharges between the two LiDAR surveys at Belluno gauging station. 
Terra Photo (Microstation Application $\left.{ }^{\circledR}\right)$. In ArcGIS 10 environment (ESRI $\left.{ }^{\circledR}\right)$, the pixel size of the photographs was then converted from $0.15 \mathrm{~m}$ to $0.5 \mathrm{~m}$ and wet areas manually digitalized. LiDAR points representing water level elevation $(Z w l)$ were extracted along the boundaries of "wet area" polygons, spaced out about $10 \mathrm{~m}$ from each other and interpolated using a "Kriging" method. Values of colour band intensity and $Z w l$ were added to the DGPS points captured in water channels in order to obtain a shapefile consisting of: intensity of the three colour bands, red (R), green $(\mathrm{G})$, blue (B), river-bed elevation (Zwet) and water surface elevation $(Z w l)$. The water depth in the channel was calculated as: $D p h=Z w l-Z w e t$.

\subsection{Elaboration of the Bathymetric Model}

Water depth represented, at this point, our dependent variable, whereas the three colour bands ( $R, G$ and $B$ ) our independent variables. $80 \%$ of the dataset was used to calibrate the depth-colour model, while the remaining $20 \%$ of the points were utilized to check efficiency and choose the best final model version. An empirical linear model according to the procedure explained by Moretto et al. [5] was then tested and all the three colour bands, their possible interactions and square and cubic terms were included in the predictive model (Eq. (1)):

$$
\begin{gathered}
D p h=\alpha+\beta_{0} R+\beta_{1} G+\beta_{2} B+\beta_{7} R^{2}+\beta_{8} G^{2} \\
+\beta_{9} B^{2}+\beta_{10} R^{3}+\beta_{11} G^{3}+\beta_{12} B^{3+} \beta_{3} R B \\
+\beta_{4} R G+\beta_{5} G B+\beta_{6} R G B
\end{gathered}
$$

where, $\alpha$ and $\beta_{x}$ are the calibration coefficients in the depth-colour regression. The significance of each component was tested deleting elements with negative results in the statistical testing. The regressions were performed using $\mathrm{R}^{\circledR}$ statistical package, by two methods: the traditional regression approach and the AICc (Akaike Information Criterion corrected) Index [30]. The first testing procedure investigates the statistical significance of each variable $(P$-value $<0.05)$, while the second method elaborates all relevant models, starting from the most complex plausible model and finally creating a ranking (lower values are correlated with best performances). The model featuring the lowest error was used to build the "RDPH (raw channel depth raster)".

\subsection{Generation and Validation of Hybrid DTMs}

The "RDPH" was obtained by applying the best regression model to the georeferenced aerial images and then transforming them into point layers. The points were then filtered to eliminate wrong or suspicious elements, mainly due to sunlight reflection, turbulence and wood or sediment components above water surface. The filtering of incorrect points was carried out as described by Moretto et al. [5], assuming that areas of abrupt slope variations in neighboring pixels, likely represented potential error of estimated depth. Through the semi-automatic creation of a "curvature raster" (ArcGIS tool ${ }^{\circledR}$ ), curvature pixel values were analyzed and implausible depth differences (greater than $0.5 \mathrm{~m}$ ), according with riffle-pool morphology and DTMs pixel size of our study case, were removed. Finally, outlier points (upper and lower implausible pixels, $<5 \%$ of the total distribution) were also deleted. The corrected points derived by the $D p h$ model were integrated with the information of the corresponding $Z w l$ in order to obtain the expected river channel elevation for each point $(Z w e t=D p h+Z w l)$.

Hybrid DTMs assimilating Zdry points derived from LiDAR survey and Zwet points inferred by colour bathymetry were then created using natural neighbor interpolation. HDTM (Hybrid DTM) models were validated separately (dry and wet areas) through comparison with DGPS control points.

\subsection{DoD (DEMs of Difference) Output}

Additional elaborations of DEM differencing were carried out in order to observe and discuss the morphological changes caused by the 2010 flood events. In this sense, the significance of the bathymetric method can be visually tested and 
acknowledged as important element to improve sediment budget estimates.

\section{Results}

\subsection{Production of Bathymetric Models from Colour Bands}

From statistical regressions performed using the two previously described methods (traditional regression and AICc), two bathymetric models for each inter-flood period were obtained. All three colour bands proved to be significantly correlated with water depth; also interactions and square and cubic terms were considered meaningful elements of the equation (for the presence of a non-linear regression in the correlation)

In 2010, the traditional regression procedure has performed a slightly better output model in respect to AICc:

$$
\begin{aligned}
& D p h=16.96+0.06222 R-0.01419 G-0.2581 B \\
& -0.0001518 R^{2}+0.002002 B^{2}-0.000005091 B^{3}(2)
\end{aligned}
$$

where, Dph is water depth and R, G and B are red, green and blue colour bands, respectively. The control operated comparing the remaining 20\% DGPS points has highlighted, in 2010, a weighted vertical error of \pm $0.18 \mathrm{~m}$ and a related standard deviation of $\pm 0.17 \mathrm{~m}$ for Belluno sub-reach and $\pm 0.28 \mathrm{~m}$ and $\pm 0.22 \mathrm{~m}$ for Praloran sub-reach (Table 1).

Similarly, a regression model for 2011 considering the most reliable results in the traditional method was performed:

$$
\begin{gathered}
\text { Dph }=10.83-0.004607 R+0.009665 G- \\
0.04102 B-0.000205 R^{2}-0.0006412 G^{2} \\
+0.0002062 B^{2}+0.000002987 G^{3}+ \\
0.0005447 R G+0.0005339 R B- \\
0.000004473 R G B
\end{gathered}
$$

In this case, the weighted vertical error accounts for $\pm 0.20 \mathrm{~m}$ and the correlated standard deviation for \pm $0.16 \mathrm{~m}$ in Belluno sub-reach, while Praloran sub-reach features values of $\pm 0.19 \mathrm{~m}$ and $\pm 0.15 \mathrm{~m}$, respectively (Table 2).

The two models proved to be statistically significant $(P$-value $<0.05)$, highlighting the important contribution of all three colour bands to channel depth estimation. In Fig. 3, a comparison between an aerial image and its related bathymetric output (Belluno sub-reach) is presented. In-channel depth variations appear to be well represented by the model which produces well-proportioned and fluid depth transitions.

\subsection{Creation of Accurate Hybrid DTMs}

After the filtering process, and removal of implausible wet points, LiDAR and bathymetric-derived surveys were integrated to create

\begin{tabular}{|c|c|c|c|c|}
\hline \multirow{2}{*}{2010} & \multicolumn{2}{|c|}{ Belluno } & \multicolumn{2}{|c|}{ Praloran } \\
\hline & Dry areas (LiDAR) & Wet areas (bathymetry) & Dry areas (LiDAR) & Wet areas (bathymetry) \\
\hline Accuracy (m) & \pm 0.26 & \pm 0.18 & \pm 0.22 & \pm 0.28 \\
\hline Standard Dev. (m) & \pm 0.17 & \pm 0.17 & \pm 0.19 & \pm 0.22 \\
\hline Control points & 918 & 411 & 618 & 177 \\
\hline
\end{tabular}
Hybrid DTMs featuring a cell size of $0.5 \mathrm{~m}$ and using a "natural neighbor" interpolation.

\begin{tabular}{|c|c|c|c|c|}
\hline \multirow{2}{*}{2011} & \multicolumn{2}{|c|}{ Belluno } & \multicolumn{2}{|c|}{ Praloran } \\
\hline & Dry areas (LiDAR) & Wet areas (bathymetry) & Dry areas (LiDAR) & Wet areas (bathymetry) \\
\hline Accuracy (m) & \pm 0.24 & \pm 0.20 & \pm 0.24 & \pm 0.19 \\
\hline Standard Dev. (m) & \pm 0.15 & \pm 0.16 & \pm 0.18 & \pm 0.15 \\
\hline Control points & 388 & 2,300 & 294 & 1,634 \\
\hline
\end{tabular}

Fig. 4 is an example of HDTM of Belluno sub-reach in 2010. Visible, is a clear alternation of in-channel landforms (riffle-pool). The accuracy of river-bed

Table 1 Accuracy analysis of LiDAR-derived and bathymetric-derived areas for 2010.

Table 2 Accuracy analysis of LiDAR-derived and bathymetric-derived areas for 2011. 


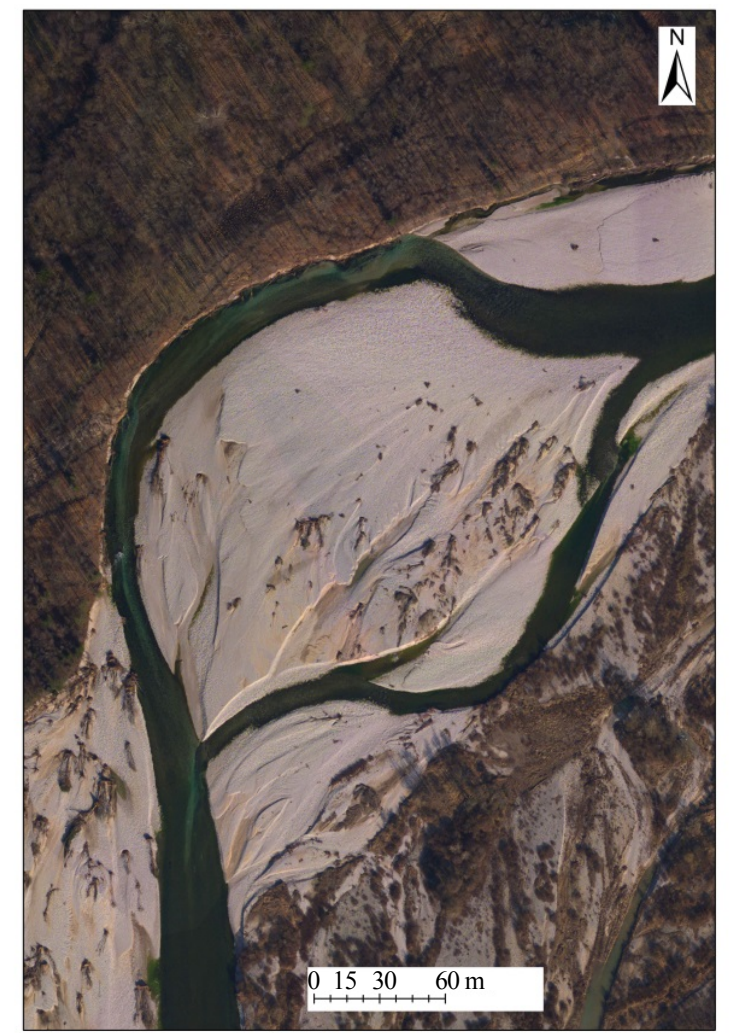

(a)

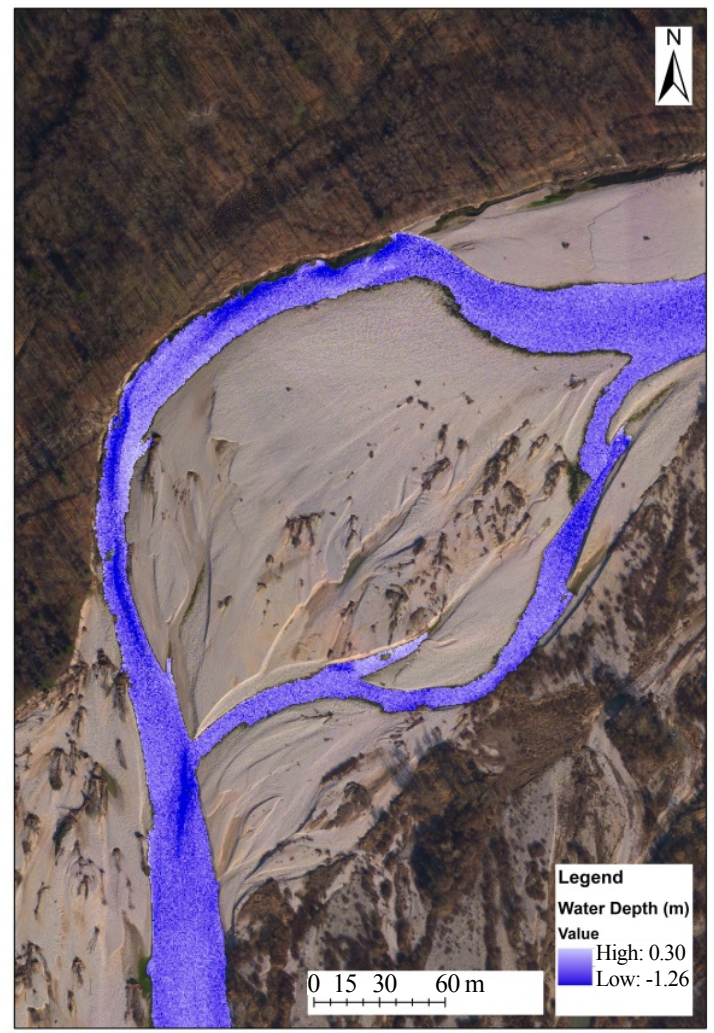

(b)

Fig. 3 Comparison between (a) the aerial image and (b) its correspondent colour bathymetry output, Belluno sub-reach (2011).

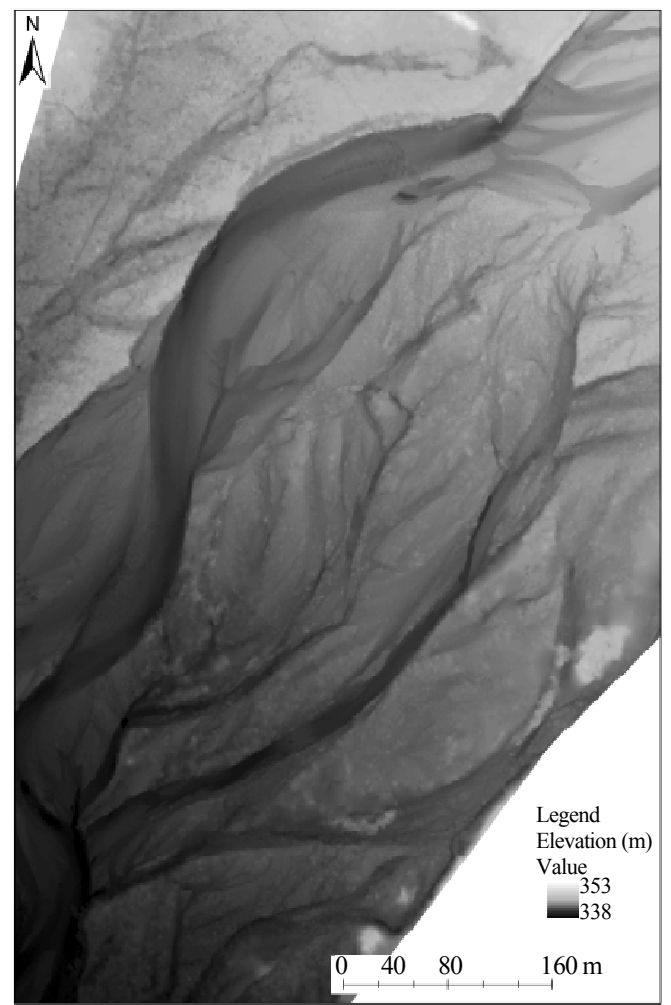

Fig. 4 Portion of the hybrid DTM of Belluno sub-reach (2010). surfaces represents a helpful amelioration in the analysis of geomorphic changes.

\section{Discussion}

\subsection{Comparison between LiDAR and Bathymetric Accuracy}

The evaluation of HDTMs accuracy was carried out separating dry LiDAR-derived areas from wet bathymetric-derived areas (Tables 1 and 2). In both considered years, the accuracy results regarding bathymetric-inferred points proved to be comparable with LiDAR average vertical errors. With the exception of the wet area of Praloran sub-reach (2010), where vertical precision features the highest error $( \pm$ $0.28 \mathrm{~m}$ ), bathymetric surfaces show better levels of accuracy in respect to dry LiDAR zones.

In this sense, channel forms delineated with this integrated technique contribute to achieve more reliable and meaningful erosion and deposition volumes. In Fig. 5, a comparison between DGPS and 
HDTM channel cross-sectional profiles is presented: river-bed points appear to be fairly well replicated.

Nevertheless, the bathymetric output obtained in this study resulted in a lower accuracy in respect to the results featured in Moretto et al. [5] (Brenta River). This lower resolution is likely due to differences in governable factors, such as number of surveyed DGPS points or imagery quality as well as uncontrollable causes, such as shadows or water turbulence. In our case, DGPS control points feature quiet different amounts among analyzed sub-reaches and years, indicating weighted acquisition of points as the most suitable approach for future accuracy evaluations. Nevertheless, it is fundamental to perform LiDAR and aerial images surveys with the best light conditions (summer and around midday to avoid shadows) and the lowest water suspended loads.

\subsection{Analysis of Geomorphic Changes}

Through the creation of accurate HDTMs, the magnitude of geomorphic changes can be assessed. In Fig. 6, we observe an example of DoD (DEM of Difference) of Belluno sub-reach, derived from 2010 and 2011 integrated models. Even though, in this study, we do not aim at estimating a total sediment budget, this visual inspection shows a predominance of erosion processes occurring within wet areas (in-channel). Surface outputs derived only from LiDAR surveys would result limiting and ineffective in areas characterized by water components. This fact underlines once again the importance of the bathymetric method to improve surface models, especially regarding in-channel areas.

The variables accounting for hydraulic hazard in fluvial environments, as sediment and vegetation dynamics can be accurately estimated and more meaningful restoration and protections measures addressed. The effects of the two flood events occurred in November-December 2010 appear visually clear (notable is the $60 \mathrm{~m}$ lateral erosion on the hydrographic right of Fig. 6-Belluno sub-reach), offering interesting starting points for future management purposes.

\subsection{The Role of Longitudinal Bank Protections}

Using the results of the DoDs, we have focused our attention and tried to interpret two significant bank erosions of stable vegetated areas that occurred downstream of two longitudinal bank protections (formed by boulders) at Belluno sub-reach. As we can see in Fig. 7, the three dimensional extent of the scour processes derived from the DoD has been isolated as well as the remaining stable zones affected

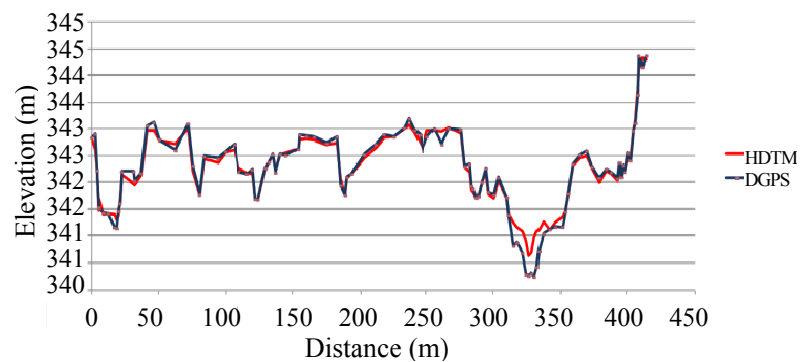

Fig. 5 Comparison between DGPS and HDTM cross-sections of Belluno sub-reach (2011).

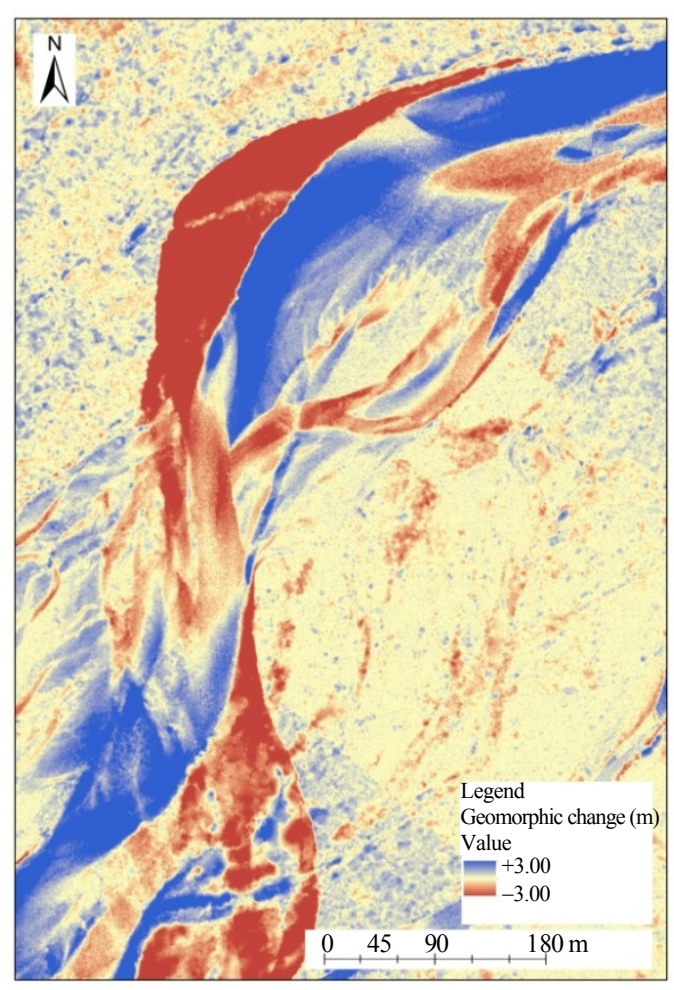

Fig. 6 Portion of DoD of Belluno sub-reach. 


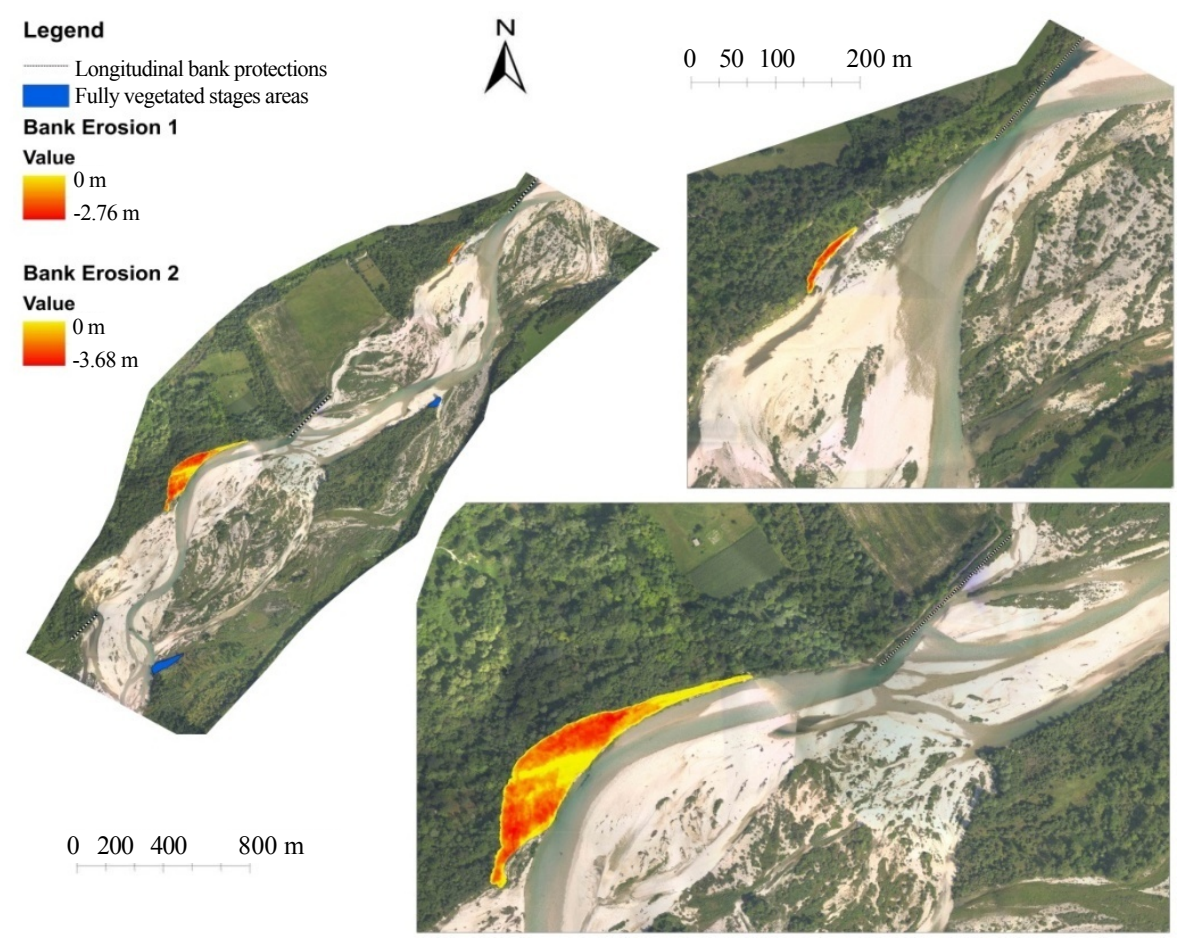

Fig. 7 Erosion of stable areas in Belluno sub-reach.

by lateral erosion. Bank erosion No. 2 experienced the most significant change with a maximum depth of $-3.68 \mathrm{~m}$, a lateral shift of $60 \mathrm{~m}$, a surface equal to $10,413 \mathrm{~m}^{2}$ and a volume of 24,063 $\mathrm{m}^{3}$ (Table 3). In Fig. 7 , a common trend concerning the two bank erosions emerges: each point of bank erosion appear to take place with similar dynamics downstream of longitudinal protections. In this case, the installation of boulder structures to prevent lateral migration of the channel appears not effective or thought within a comprehensive strategy. In fact, the problem of eroding banks seems to have been shifted downstream and, potentially, upstream of the second longitudinal intervention, a growing lateral erosion threatening, beside the marginal field, the own existence of the artificial structure is evident.

Another interesting consideration concerns the type of soil being eroded at the banks as consequence of the flood events of November and December 2010: the two lateral scours removed stable vegetated areas. These cohesive zones are normally the less prone to erosion and require not ordinary hydrodynamic conditions to be mobilized. Moreover, if we compare the areal and volumetric incidence of the two bank erosions over the total amount of stable areas being eroded, we can notice that they are significantly predominat, accounting for $81 \%$ and $84 \%$, respectively (Table 4 ).

In this sense, we can infer that longitudinal bank protections could have led, during the floods, to an increase of water velocity through a "channelization effect" that, shifting flow and erosion dynamics downstream, has intensified the eroding potential enabling the mobilization of a larger amount of stable soil.

Table 3 Characteristics of the erosions in stable areas.

\begin{tabular}{llll}
\hline Measure & Bank erosion 1 & Bank erosion 2 & Erosion in remainings table areas \\
\hline Maximum depth $(\mathrm{m})$ & -2.76 & -3.68 & -2.86 \\
Maximum width $(\mathrm{m})$ & 11 & 60 & 25 \\
Area $\left(\mathrm{m}^{2}\right)$ & 567 & 10,413 & 2,572 \\
Volume $\left(\mathrm{m}^{3}\right)$ & 1,038 & 24,063 & 4,917 \\
\hline
\end{tabular}


Table 4 Incidence of the two major bank erosions.

\begin{tabular}{lll}
\hline Measure & $\begin{array}{l}\text { Total erosion } \\
\text { in stable areas }\end{array}$ & $\begin{array}{l}\text { Incidence }(\%) \text { of bank erosions } \\
\text { and } 2 \text { on total erosion of } \\
\text { stable areas }\end{array}$ \\
\hline Area $\left(\mathrm{m}^{2}\right)$ & 13,550 & 81 \\
Volume $\left(\mathrm{m}^{3}\right)$ & 30,017 & 84 \\
\hline
\end{tabular}

Future management strategies should take into consideration the previous described issues, trying to adopt a comprehensive approach in the analysis of fluvial environments and trying to answer the following questions: Are the planned protection measures able to avoid the shifting of bank erosion? Would it be better to artificially intervene or maybe would it be more convenient to give the river room to adjust through compensative purchases of land from the marginal terrain owners?

\section{Conclusions}

The present work has proposed a useful method to integrate LiDAR-derived DTMs and better represent wet areas. Considering that most part of geomorphic changes occur within river channels, the bathymetric output acquires even more significance which is also confirmed by fairly high levels of accuracy shown in the validation process. Starting from these reliable integrated surface models, more precise geomorphic analyses can be performed and meaningful rates of change achieved. In this sense, the predominance of erosion processes and, specifically, the occurrence of two major bank erosions were successfully assessed. The thesis inferred in this paper about a possible connection and intensification effect of longitudinal protections on the two significant lateral scours has finally given rise to new perspectives in planning future river interventions.

\section{Acknowledgments}

This research was founded by the Strategic Research Project "GEORISKS geological, morphological and hydrological processes: monitoring, modeling and impact in North-Eastern Italy" and by the Project "SedAlp: sediment management in Alpine basins, integrating sediment continuum, risk mitigation and hydropower". A special thanks to Justin Stout for his help in the revision process.

\section{References}

[1] D.A. Sear, M.D. Newson, C.R. Thorne, Guidebook of applied Fluvial Geomorphology, Institution of Civil Engineers, London, 2003.

[2] N.S. Gurnell, L. Zanoni, Multi-thread river channel: A perspective on changing European alpine river systems, Aquatic Sciences 71 (3) (2009) 253-265.

[3] N. Surian, L. Ziliani, F. Comiti, M.A. Lenzi, L. Mao, Channel adjustments and alteration of sediment fluxes in gravel-bed rivers of north-eastern Italy: Potentials and limitations for channel recovery, River Research and Applications 25 (2009) 551-567.

[4] F. Comiti, M. da Canal, N. Surian, L. Mao, L. Picco, M.A. Lenzi, Channel adjustments and vegetation cover dynamics in a large gravel bed river over the last 200 years, Geomorphology 125 (2011) 147-159.

[5] J. Moretto, E. Rigon, L. Mao, L. Picco, F. Delai. M.A. Lenzi, Assessing morphological changes in gravel bed rivers using Lidar data and colour bathymetry, erosion and sediment yields in the changing environment, International Association of Hydrological Sciences (IAHS) Publication 356 (2012) 419-427.

[6] J. Moretto, F. Delai, E. Rigon, L. Picco, L. Mao, M.A. Lenzi, Assessing short term erosion-deposition processes of the Brenta River using Lidar surveys, WIT Transactions on Engineering Sciences 73 (2012) 149-160.

[7] J. Moretto, E. Rigon, L. Mao, L. Picco, F. Delai, M.A. Lenzi, Medium- and short-term channel and island evolution in a disturbed gravel bed river (Brenta River, Italy), Journal of Agricultural Engineering 43 (4) (2012) 176-188.

[8] L. Picco, L. Mao, E. Rigon, J. Moretto, D. Ravazzolo, F. Delai, et al., An update of the sediment fluxes investigation in the Rio Cordon (Italy) after 25 years of monitoring, Journal of Agricultural Engineering 43 (3) (2012) 108-113.

[9] G. Kaless, L. Mao, M.A. Lenzi, Regime theories in gravel-bed rivers: Models, controlling variables, and applications in disturbed Italian rivers, Hydrological Processes 28 (4) (2014) 2348-2360.

[10] G. Heritage, D. Hetherington, Towards a protocol for laser scanning in fluvial geomorphology, Earth Surface Processes and Landforms 32 (1) (2007) 66-74.

[11] D.J. Milan, G.L. Heritage, D. Hetherington, Application of a 3D laser scanner in the assessment of erosion and deposition volumes and channel change in a proglacial 
river, Earth Surface Processes and Landforms 32 (11) (2007) 1657-1674.

[12] W.A. Marcu, M.A. Fonstad, Optical remote mapping of rivers at sub-meter resolutions and watershed extents, Earth Surface Processes and Landforms 33 (1) (2008) 4-24.

[13] S.N. Lane, S.C. Reid, R.M. Westaway, D.M. Hicks, Remotely sensed topographic data for river channel research: The identification, explanation and management of error, in: R.E.J. Kelly, N.A. Drake, S.L. Barr (Eds.), Spatial Modeling of the Terrestrial Environment, John Wiley \& Sons, Chichester, UK, 2004, pp. 157-174.

[14] P.E. Carbonneau, S.N. Lane, N.E. Bergeron, Feature based image processing methods applied to bathymetric measurements from airborne remote sensing in fluvial environments, Earth Surface Processes and Landforms 31 (2006) 1413-1423.

[15] C.J. Legleiter, D.A. Roberts, A forward image model for passive optical remote sensing of river bathymetry, Remote Sensing of Environment 113 (2009) 1025-1045.

[16] P.J. Kinzel, C.W. Wright, J.M. Nelson, A.R. Burman, Evaluation of an experimental lidar for surveying a shallow, braided, sand-bedded river, Journal of Hydraulic Engineering 133 (2007) 838-842.

[17] D.M. Hicks, Remotely sensed topographic change in gravel riverbeds with flowing channels, in: M. Church, P.M. Biron, A.G. Roy (Eds.), Gravel-bed Rivers: Processes, Tools, Environments, Wiley-Blackwell, Chichester, UK, 2012, pp. 303-314.

[18] C.D. Rennie, Mapping water and sediment flux distributions in gravel-bed rivers using ADCPs, in: $\mathrm{M}$. Church, P.M. Biron, A.G. Roy (Eds.), Gravel-Bed Rivers: Processes, Tools, Environments, Wiley-Blackwell, Chichester, UK, 2012, pp. 342-350.

[19] J.M. Wheaton, J. Brasington, S.E. Darby, D.A. Sear, Accounting for uncertainty in DEMs from repeat topographic surveys: Improved sediment budgets, Earth Surface Processes and Landforms 35 (2010) 136-156.

[20] L. Reusser, P. Bierman, Accuracy assessment of Lidar-derived DEMs of bedrock river channels: Holtwood Gorge, Susquehanna River, Geophysical Research Letters, Dec. 2007, http://onlinelibrary.wiley.com/doi/10.1029/
2007GL031329/abstract (accessed Dec. 2007).

[21] B. Notebaert, G. Verstraeten, G. Goversand J. Poesen, Qualitative and quantitative applications of lidar imagery in fluvial geomorphology, Earth Surface Processes and Landforms 34 (2009) 217-231.

[22] R.C. Hilldale, D. Raff, Assessing the ability of airborne lidar to map river bathymetry, Earth Surface Processes and Landforms 33 (2008) 773-783.

[23] S.J. Winterbottom, D.J. Gilvear, Quantification of channel bed morphology in gravel-bed rivers using airborne multispectral imagery and aerial photography, Regulated Rivers: Research and Management 13 (1997) 489-499.

[24] W.A. Marcus, C.J. Legleiter, R.J. Aspinall, J.W. Boardman, R.L. Crabtree, High spatial resolution hyperspectral mapping of in-stream habitats, depths and woody debris in mountain streams, Geomorphology 55 (2003) 363-380.

[25] C.J. Legleiter, Mapping river depth from publicly available aerial images, River Research and Applications 29 (2012) 760-780.

[26] P. Prosser, A.O. Hughes, I.D. Rutherfurd, Bank erosion of an incised upland channel by subaerial processes: Tasmania, Australia, Earth Surface Processes and Landforms 25 (2000) 1085-1101.

[27] T.C.T. Hubble, B.B. Docker, I.D. Rutherfurd, The role of riparian trees in maintaining riverbank stability: A riview of Australian experience and practice, Ecological Engineering 36 (2010) 292-304.

[28] H.P. Wolfert, Geomorphological Change and River Rehabilitation: Case Studies on Lowland Fluvial Systems in the Netherlands, Alterra Scientific Contributions 6, Alterra Green World Research, Wageningen, The Netherlands, 2001, p. 200.

[29] J. Vandenberghe, J.J.W. de Moor, G. Spanjaard, Natural change and human impact in a present-day fluvial catchment: The Geul River, Southern Netherlands, Geomorphology 159-160 (2012) 1-14.

[30] P. Burnham, D.R. Anderson, Model Selection and Multimodel Inference: A Practical Information-Theoretic Approach, 2nd ed., Springer, New York, USA, 2002, p. 488 . 